\title{
O MUSEU DE CIÊNCIAS COMO ESPAÇO DE PROVOCAÇÃO DOS SENTIDOS
}

\author{
THE SCIENCE MUSEUM AS A SPACE FOR THE PROVOCATION OF \\ THE SENSES
}

\author{
Adair de Aguiar Neitzel \\ Doutora em Literatura, Professora na Universidade do Vale do Itajaí - UNIVALI \\ Itajaí, Santa Catarina - Brasil \\ neitzel@univali.br \\ Mônica Zewe Uriate \\ Doutora em Educação, Professora na Universidade do Vale do Itajaí - UNIVALI \\ Itajaí, Santa Catarina - Brasil \\ uriarte@univali.br \\ Kátia Franklin \\ Doutora em Educação pela Universidade do Vale do Itajaí - UNIVALI \\ Itajaí, Santa Catarina - Brasil \\ katiab@univali.br
}

\begin{abstract}
Resumo: Esta pesquisa teve, como tema, a educação estética e, como objetivo, discutir como o museu de ciências pode ser também espaço de provocação dos sentidos, de educação estética. Museus de arte são indiscutivelmente lugares de educação estética e os museus de ciências geralmente são relacionados a espaços de conhecimento, com foco no inteligível e não no sensível. Esta pesquisa qualitativa ocorreu no Museu Oceanográfico da Universidade do Vale do Itajaí, Balneário Piçarras, Santa Catarina, Brasil, e os instrumentos de coleta de dados foram diários de campo dos pesquisadores, fotos e entrevista com o curador do museu. A análise da entrevista e do diário pautou-se na análise de conteúdo de Franco (2008) e a das imagens segundo os conceitos de punctum e studium, de Barthes (2010). O aporte teórico de sustentação contou com Bachelard (2000), Franklin (2019), Heidegger (2015) e Martins (2012, 2014), entre outros. Como resultados, foi possível evidenciar que: o museu oceanográfico possui espaços esteticamente planejados, cuja organização, iluminação e exploração de sonoridades afetam o sujeito, provocando-o à experiência. Identificou-se, também, que as escolhas efetuadas pela curadoria foram intencionais para sensibilizar o público e que elas possibilitaram que espaços e objetos fossem propositores de experiências porque ampliam o potencial estético do museu. No entanto, como a experiência é um movimento individual, nem todos podem por ele ser afetados.
\end{abstract}

Palavras Chave: Educação estética. Museu de ciências. Espaços propositores. Objetos propositores.

\begin{abstract}
This research had as its theme the aesthetic education and as an objective to discuss how the science museum can also be a space of provocation of the senses, of aesthetic education. Art museums are arguably places of aesthetic education and science museums are generally related to spaces of knowledge, with a focus on the intelligible and not the sensitive. This qualitative research took place at the Oceanographic Museum of the Vale do Itajaí University, located in Balneário Piçarras, Santa Catarina, Brazil, and the data collection instruments were researchers' field diaries, photographs and interviews with the museum curator. The analysis of the interview and the diary was based on the content analysis of Franco (2008) and the images according to the concepts of punctum and studium, based on Barthes (2010). The theoretical support counted on Bachelard (2000), Franklin (2019), Heidegger (2015) and Martins (2012, 2014), among others. As a result, it was possible to show that: the oceanographic museum has aesthetically planned spaces, whose organization, lighting and exploration of sounds affect the subject, causing him/her to experience. It was also identified that the choices made by the curators were intentional to raise public awareness and that they enabled spaces and objects to be proposers of experiences because they expand the aesthetic potential of the museum. However, as the experience is an individual movement, not everyone can be affected by it.
\end{abstract}

Key-words: Aesthetic education. Science museum. Proposing spaces. Proposing objects.

\section{Para citar - (ABNT NBR 6023:2018)}

NEITZEL, Adair de Aguiar; URIATE, Mônica Zewe; FRANKLIN, Kátia. O museu de ciências como espaço de provocação dos sentidos. Eccos - Revista Cientifica, São Paulo, n. 53, p. 1-17, e16792, abr./jun. 2020. Disponível em: https://doi.org/10.5585/eccos.n53.16792. 


\section{Introdução}

Vimos, ao longo de nossa caminhada de pesquisadoras, problematizando como os espaços formais e não formais de educação podem contribuir para a educação estética dos sujeitos. Esta pesquisa, dando continuidade a nossas investigações, propõe-se a discutir como o museu de ciências pode ser também espaço de provocação dos sentidos, de educação estética, pois, normalmente, as pessoas idealizam os museus de ciências como espaços apenas de conhecimento científico, com foco no inteligível e não no sensível. Para Gohn (2011), o museu é um espaço não formal de educação porque estimula um “[...] processo de formação humana, criativo e de aquisição de saberes e certas habilidades" (GOHN, 2011, p. 341), que não estão disponíveis no ambiente escolar, mas que potencializam processos de ensino e de aprendizagem.

Pesquisas como as de Silva e Bitencourt (2018) e de Martins (2014) apontam para as potencialidades educativas de espaços não formais como os museus, assim como para a importância de sua democratização e da necessidade de revitalizar-se o conceito de mediação cultural. Franklin (2019), diferentemente de Silva e Bitencourt (2018), não enfatiza o museu como um complemento ao trabalho realizado em sala de aula, reforçando sua função educativa, mas a autora defende a tese de que os objetos da ciência podem ser propositores tanto de sensibilidades como de inteligibilidades, de modo a problematizar quais as possibilidades de educação estética dos Museus de Ciências Naturais.

Esses museus foram escolhidos para a investigação de Franklin (2019) por tratar-se de um espaço educativo que acolhe, por meio de seu acervo científico, formas expositivas que evidenciam as espécies ou os artefatos, constituindo-se em um espaço divulgador das ciências, com potência para a educação estética, também denominada por Duarte Júnior (2010) como “estésica". Esta "[...] refere-se primordialmente ao desenvolvimento dos sentidos de maneira mais acurada e refinada, de forma que nos tornemos mais atentos e sensíveis aos acontecimentos em volta tomando melhor consciência deles" (DUARTE JÚNIOR, 2010, p. $185)$.

Para Neitzel, Pontes e Neitzel (2020, p. 269), “[...] a educação estética dá-se não apenas pelo contato íntimo com as artes, mas com o mundo e, por isso, a forma como nos relacionamos com ele, o valor que damos às coisas que nos rodeiam, contribuem para nos estesiar ou anestesiar", uma assertiva que encontra respaldo na pesquisa de Carvalho e Lopes (2016). Segundo as pesquisadoras, os museus hoje são reconhecidos “[...] como lócus privilegiado de educação não formal que podem possibilitar dimensões distintas da experiência humana, como: 
a cognitiva, afetiva e psicomotora" (CARVALHO; LOPES, 2016, p. 912). Se o Museu de Ciências Naturais é um espaço cuidadosamente pensado para provocar sensações no público, a sensibilizá-lo, a refinar seus gostos e seus sentidos, torna-se um espaço que combate a anestesia. A curadoria do museu ao organizá-lo pensa no público, nas percepções que aqueles objetos dispostos daquela maneira podem causar, e, nesse sentido, a sua organização, a sua iluminação, a sua legenda, o seu espaço de circulação, o seu material educativo, entre outros elementos, são fundamentais para provocar no público a interação e a estesia. "Museus são espaços de conhecimento, informação, mas também de sonho, de devaneio, de estesia, de fruição" (FRANKLIN et al., 2017, p. 142).

O museu de ciências pode ser, assim, um espaço de provocação dos sentidos, trazendo à tona as subjetividades do público e educando esteticamente por meio do diálogo entre sensível e inteligível. Martins (2012) enfatiza que o museu é um lugar que acolhe o público, conceito que nos convida a pensá-lo não apenas como um repositório, um espaço de coleções, mas um espaço aberto à interação: “[...] museus não são apenas lugares de guarda da história dos objetos e dos objetos da história. Hão de acolher o visitante [...] para que a preservação do patrimônio cultural valorize em cada um de nós a nossa própria história imantada nas coisas [...]" (MARTINS, 2012, p. 44).

Partimos desses estudos para discutir, neste artigo, a concepção do museu como espaço não apenas de produção de conhecimentos inteligíveis, mas também de sensibilidades, os quais acontecem por meio da interação com os objetos museais e com as informações que estão nele disponíveis, assim como na interação com os pares e os mediadores. Martins (2018, p. 580) lembra que é "[...] no âmbito das relações humanas afetivas, transcendentes, consequentes, temporais que a educação pode ser compreendida como atividade museal”. Quando o público é provocado a experiências sensíveis, quando ele é afetado pelo que vê, ouve e toca, quando ele faz a experiência no sentido que Heidegger (2015) anuncia, o museu torna-se espaço da experiência, um espaço habitável, na concepção de Bachelard (2000).

Os estudos de Heidegger (2015) sobre a linguagem podem auxiliar-nos a compreender a premissa do museu como espaço de provocações de sentidos que repercute na educação estética do público. Para o filósofo, “[...] provocar é evocar uma proximidade” (HEIDEGGER, 2015, p. 16). Cabe questionarmo-nos: Como evocar essa proximidade? Novamente o filósofo nos ajuda: “[...] evocar no sentido originário de deixar vir a intimidade de mundo e coisa é propriamente chamar" (HEIDEGGER, 2015, p. 22). Entendemos que há um sentido aquietado nas coisas, nos objetos museais, que é preciso evocar, e a ação do curador é fundante para criar esse movimento de intimidade, de proximidade, de chamar. Ao fazer isso, as peças do museu 
de ciências, que eram, antes de ali estar, seres da natureza, passam a agregar outros sentidos. Esse movimento não é de desapropriação, mas de justaposição e de aglutinação, pois os objetos "gestam e gestualizam um mundo" (HEIDEGGER, 2015, p. 20) e pelas mãos do curador ele é chamado a vir, a ser ressignificado.

Bachelard (2000) provoca-nos a pensar os espaços dos museus de ciências segundo uma fenomenologia da imaginação, para além da sua função educativa e de comunicação, de manipulação, da experiência científica. Seus estudos alimentam a ideia de um espaço habitável pela explosão de imagens poéticas e construção de memórias que repercutem e implicam a educação estética das pessoas. Por sua dinamicidade e sua sonoridade, em outras palavras, pela sua possibilidade de oportunizar a produção de sentidos e a repercussão, as imagens colhidas nos museus na relação estabelecida pelo sujeito com os objetos possuem uma subjetividade e força que podem ser potencializadas pela ação curatorial.

Compreender o museu como um espaço habitável é, assim, observá-lo com sensibilidade, investindo na produção de devaneios poéticos. Nesse sentido, o museu passa a ser espaço de movimentos e de ressonâncias e quiçá de repercussões, lembrando que: “As ressonâncias se dispersam nos diferentes planos da nossa vida no mundo, a repercussão nos chama a um aprofundamento de nossa própria existência” (BACHELARD, 2000, p. 7). Essa concepção de museu como espaço estético, habitável e de experiência é recente, pois foi a partir do século XX que "[...] de lugar de guarda, estudo e conservação, o museu amplia suas funções passando a ser percebido também como lugar de educação, de lazer e de apreciação, independentemente de sua classificação [...]" (NEITZEL et al., 2017, p. 326).

Um museu é um espaço educativo em um ambiente não formal que pode oportunizar a produção de muitas narrativas pessoais, pois, além de ativar nossas memórias, pode nos provocar à produção de subjetividades que interferem no jogo entre imaginação e entendimento. Segundo o Caderno da Política Nacional de Educação Museal (IBRAM, 2018), um dos conceitos-chave do campo da educação museal é a educação não formal e a formação integral. A educação não formal, para Gohn (2015), é aquela que se dá a partir dos saberes gerados em ambientes que educam pelas experiências, que oportunizam, e não por um currículo prédeterminado.

A formação integral foca-se tanto nas habilidades e nas competências voltadas ao desenvolvimento intelectual, como aquelas associadas ao desenvolvimento social, emocional, físico e cultural. Essa formação é valorizada pela competência 2 da Base Nacional Comum Curricular (BNCC), quando indica a necessidade de: 
Exercitar a curiosidade intelectual e recorrer à abordagem própria das ciências, incluindo a investigação, a reflexão, a análise crítica, a imaginação e a criatividade, para investigar causas, elaborar e testar hipóteses, formular e resolver problemas e criar soluções (inclusive tecnológicas) com base nos conhecimentos das diferentes áreas. (BRASIL, 2018, p. 9).

Entendemos que o museu, quando percebido não apenas como um repositório de nossa memória cultural, mas também como espaço estésico que possibilita que as potencialidades do usuário sejam ampliadas, oportuniza a educação integral. Ele faz isso educando pelo sensível e pelo inteligível, sem apartamentos. Uma educação pelo sensível é aquela que oportuniza o pensar pelo sentir, o conhecimento pela percepção, a construção de conceitos pela intuição, o saber pela experiência, entendida como movimento, como um fazer que não se aparta do mundo vivido.

Ao adentrar um espaço museal, o sujeito da experiência realiza encontros com pessoas, objetos e espaços, os quais renovam seus saberes que oportunizam pensar e sentir. Segundo Nhoque (2019, p. 61), “[...] experiência é um conceito complexo, aberto a diferentes intepretações e intimamente ligado à noção de sujeito e sua relação com a vida". A pesquisadora enfatiza, em sua tese, com base em Heidegger, que a experiência é aquilo que nos atravessa, nos avassala, nos possibilita encontros com o outro, que nos encarna. $\mathrm{O}$ museu, sendo o espaço da experiência, é também de educação dos sentidos.

Com o contato com a materialidade presente em seus acervos, cria-se possibilidades de leituras e de interpretações a serem preenchidas. Nesse sentido, o museu também é espaço de vazios, os quais incentivam a maquinação semiótica porque os vazios abrem possibilidades de o público lançar projeções e vibrações sobre determinada peça museal. Por isso, afirmamos que a função educativa desse espaço não se restringe a repassar informações ou memórias, mas, sobretudo, oportunizar experiências que levem o sujeito da experiência à criatividade e à liberdade de pensamento, a se surpreenderem, a produzirem suas próprias memórias e imagens. A educação do sensível dá-se no fazer experiência, a qual é provocada não somente pelas escolhas dos curadores, mas também por meio das interações, do estar junto, das descobertas, como expressa o curador do Museu Oceanográfico Univali ${ }^{1}$ (MOVI):

Essa questão da provocação de tu veres um neto de mãos dadas com o avô, e os dois aprendendo juntos é o que eu queria, é o que eu buscava, das pessoas se surpreenderem, se surpreenderem com a natureza, com os organismos, com o que sabemos sobre o oceano e também sobre o que não sabemos, ficando surpresos com o quanto a gente sabe pouco sobre os oceanos. (Curador do MOVI).

De mãos dadas, aprendendo juntos. Então, o museu é lugar também de afetividades. Ao dedicarmo-nos a investigar um museu oceanográfico, buscamos um trabalho de deslocamento do conceito usual atribuído aos museus de ciências, de memória do nosso passado, de lugar de 
democratização do acesso aos bens culturais acumulados, para um espaço onde também se giram saberes sensíveis. Esse deslocamento encaminha-nos à percepção do museu como também a um espaço estésico, que promove a educação dos sentidos.

Assim, o museu é pensado como um espaço comunicante de laços afetivos. Como sinaliza Lawand (2004, p. 66), “[...] a metodologia da educação patrimonial pressupõe uma mudança de atitude com relação ao patrimônio cultural, apelando mais para o sensível e o emocional". Um deslocamento que nos oportuniza ressignificar o encontro do público com o museu para um espaço de novas produções culturais, ampliando, desse modo, os sentidos dos museus. Nessa perspectiva, o curador do MOVI aponta:

\section{[...] não adianta a gente teorizar muito não, até porque as coisas não são muito matemáticas, não está muito embasada no material e método, o museu está embasado nas sensações, o museu pode ter o mesmo conteúdo e não propiciar sensações. (Curador do MOVI).}

Esse convite para um saber sensível e perceptivo de que nos fala o curador dá-se por diversas vias, mas é dependente da forma como a curadoria pensa a exposição, porque se ela compreende o museu de ciências não apenas como um ambiente de conhecimento racional, mas também de experiências intuitivas e sensíveis, buscará criar um ambiente que provoque a estesia e dialogue com o mundo vivido, mundo este que chega a nós pelos sentidos (DUARTE JÚNIOR, 2012). Para o curador do MOVI: “O museu oceanográfico da Univali, o projeto dele foi desenvolvido para propiciar sensações, por isso que ele é uma descoberta a cada corredor. E são muitos corredores de vai e vem, uma descoberta a cada curva, e essa sensação é provocada a cada curva".

O que faz o curador? Ele cria rasgaduras evocando mundo e objetos para a nossa intimidade, encorajando o desencobrimento do objeto e do espaço onde ele se encontra. $\mathrm{O}$ curador é um mediador porque ele intermedeia nossa relação com o objeto e com o mundo das sensações que ele evoca. O objeto museal é expressão, mas não só. Os enunciados que ele carrega não estão todos prepostos, e, por isso, sua linguagem é uma múltipla enunciação. Desse modo, o sujeito da experiência não pode ficar preso a uma representação predominante da visão de mundo que nos acompanha. O objeto fala e, para ressignificá-lo, é preciso contestar o preconceito de que o museu de ciências é o espaço apenas da linguagem científica, da precisão, do conhecimento inteligível. Segundo Heidegger (2015), é preciso renunciar o que temos de pré-concebido sobre as coisas para um "re-anunciar", o que implica ver outras possibilidades de sentido, novas descobertas.

Defendemos um olhar para o museu de ciências como um espaço não formal de educação que pode possibilitar uma relação também estética com o público, dependendo de 
como o curador articula as suas narrativas aos objetos museais e de como o público interage com elas, uma vez que a experiência é sempre singular, única, pessoal e intransferível. Neste artigo, para desenvolver a problemática que anunciamos, analisaremos o espaço do Museu Oceanográfico Univali (MOVI), criado em 1987 e aberto ao público em 2015.

\section{Metodologia}

Esta é uma pesquisa qualitativa, de natureza exploratória, cujo objetivo é discutir como o museu de ciências pode ser também espaço de provocação dos sentidos, de educação estética. Ela foi desenvolvida no MOVI, que se localiza no campus da Univali, na cidade de Balneário Piçarras (Figura 1), Santa Catarina, Brasil. Esse museu está entre os quatro principais acervos de história natural do Brasil; no entanto, na temática oceanográfica, considera-se como o maior museu da América Latina. Seu acervo surgiu de uma coleção particular que, posteriormente, foi institucionalizada.

Figura 1 - Localização do museu

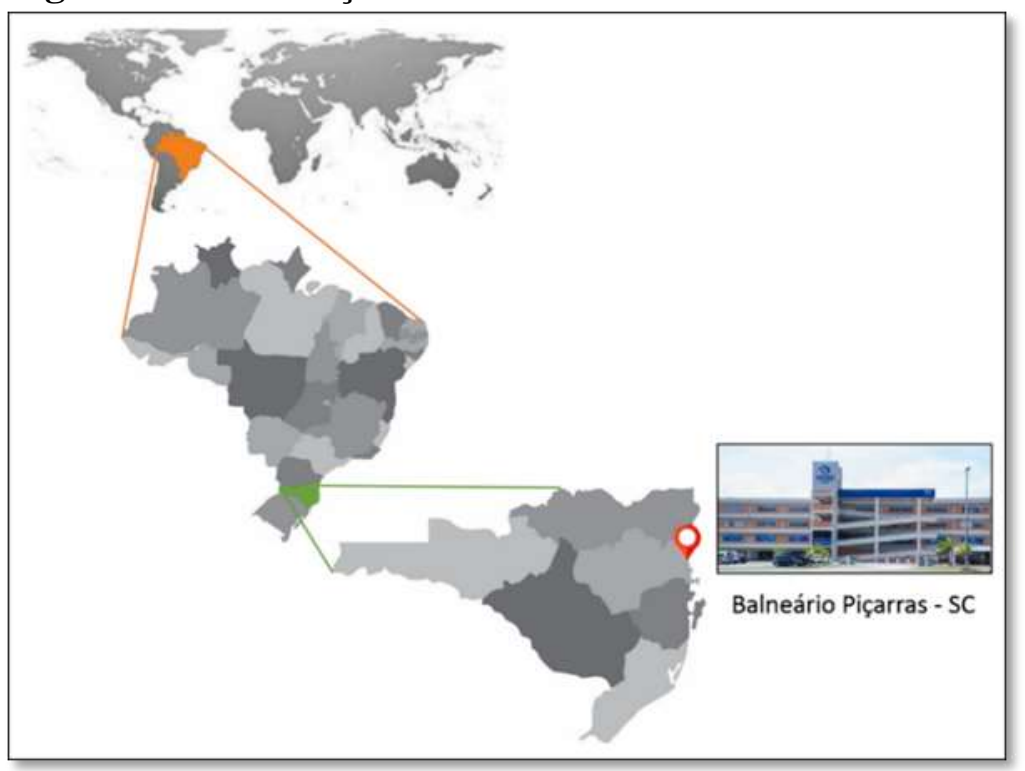

Fonte: Adaptada de Franklin (2019, p. 28).

Como instrumento de coleta de dados, optamos pelo diário de campo, pela fotografia de algumas obras e espaços museais e pela entrevista com o curador do museu. A análise das imagens pautou-se nos conceitos de punctum e studium de Barthes (2010). O diário de campo e a entrevista, por sua vez, foram analisados a partir da análise de conteúdo de Franco (2008). 


\section{Adentrando o espaço do museu}

Pensar o museu de ciências como um espaço habitável é desvelar seus matizes, seus dinamismos e sua poeticidade, pois, em uma perspectiva fenomenológica, falar do espaço não nos leva a descrevê-lo como um objeto, mas percebê-lo como um espaço no qual encontramos abrigo, um espaço cultural que "[...] chama a ação, e antes da ação a imaginação trabalha. Ela ceifa e lavra" (BACHELARD, 2000, p. 31).

Ao adentrar o espaço interno do MOVI, percebemos sua poeticidade evocada pela penumbra do ambiente que contrasta com as cores das paredes e do fundo de alguns dos expositores. Corais que, no fundo do mar, atraem pelas suas cores vibrantes, no museu, magnetizam por esse jogo de claro e rúbido. Suas formas variadas, sua textura porosa, seu exoesqueleto duro que, usualmente, remete à grande biodiversidade que ele deixou de abrigar, cativa o olhar do público que aprecia os objetos não mais pela sua função no fundo do mar, mas pela simbiose que provoca e melhora o nosso olhar. Essa ressignificação dá-se por um deslocamento dos sentidos - os espécimes deixam de apenas comunicar, são lançados como maquinarias semióticas que podem interferir no jogo subjetivo entre imaginação e entendimento.

Martins (2018) parte da imagem construída por Beatriz Sarlo de "artesanato da resistência" para falar dos museus e de suas ações como um espaço bastante potente, em cujo interior, no contato com a materialidade de seus acervos e nas possibilidades de leitura e de interpretação, pode-se dar lugar a novas criações culturais. Para a pesquisadora, um museu não deve ser compreendido apenas como um espaço de produção de serviços e informações culturais, pois ele também é um espaço onde “[...] se enfatizam os vínculos entre os sujeitos frequentadores e os objetos herdados ou construídos, materiais ou não-materiais, presentes nos museus" (MARTINS, 2018, p. 580).

As imagens cultivadas afetam e repercutem também pelo contraste que é produzido entre o escuro e a luminosidade artificial, sugerindo que estamos no fundo do mar, habitat das arraias que são demersais. Como o cotidiano do homem moderno está cheio de informações e de poucos acontecimentos, como afirma Larrosa (2016), o museu de ciências é a oportunidade de desembrutecimento dos sentidos humanos, quando ele explora o potencial estésico dos objetos por meio de luzes, de cores (Figura 2), de formas, de sabores, de texturas, de odores, educando nosso olhar, nossa audição, nosso tato, nosso paladar e nosso olfato. Um movimento que nos permite "[...] perceber de modo acurado a realidade em volta e aquelas outras não acessíveis em seu cotidiano" (DUARTE JÚNIOR, 2010, p. 26). 
Figura 2 - Corais

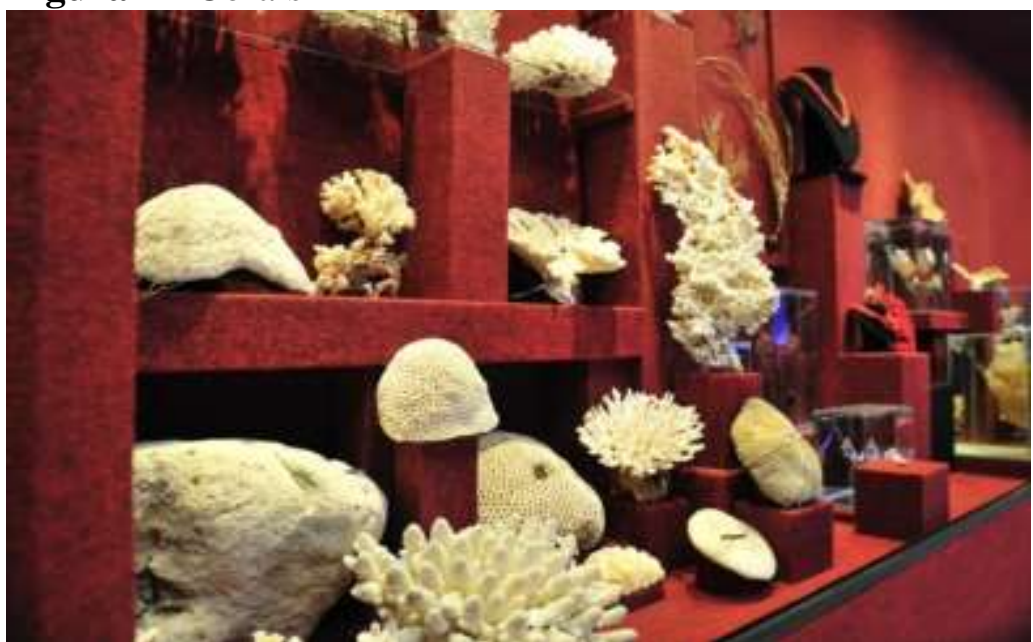

Fonte: MOVI (2019a, n.p.).

Dessa forma, um exercício inteligível e sensível é acionado não apenas pelo conhecimento que está encapsulado em cada objeto, representante cada um de uma espécie, mas pela atmosfera composta pelo seu conjunto. Uma imagem poética de súbito é provocada, e uma nova ideia é integrada a esse corpo de ideias já aceitas, estimulando a ressignificação por meio dessa explosão de sentidos. Esse movimento não pode se dar apenas pelo racional, pelo inteligível, porque esses artefatos biológicos aqui se encontram não somente como amostras do espécime. Expostos em uma lógica apreciativa (Figura 3), eles também têm uma função estética que depende dos nossos sentidos para ser compreendida.

Figura 3 - Arraias

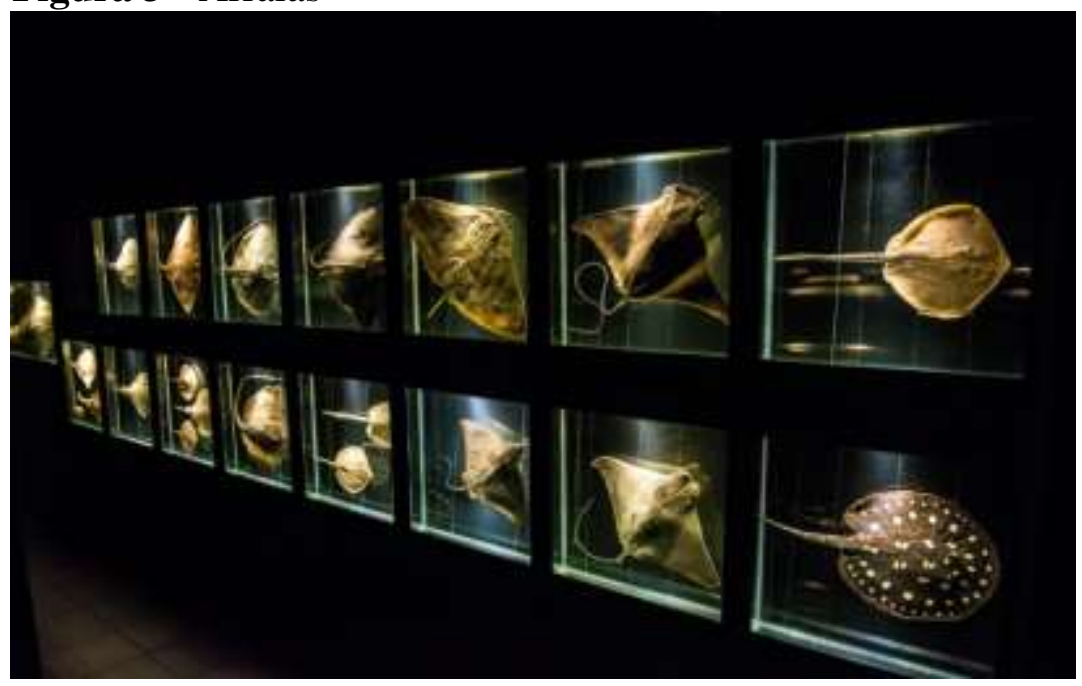

Fonte: MOVI (2019b, n.p.).

A sequência de imagens sinestésicas no MOVI que repercutem são grandes, e o desdobramento de simples imagens que guardamos em nossa memória de espécimes biológicas 
é motivado pelo conjunto de engastes possibilitados pelo curador. Utilizaremos o conceito de engaste desenvolvido por Neitzel (2009), sendo este considerado pela pesquisadora como o elemento que garante a ordenação de " [...] elementos e sentidos mais díspares, soldando esses sentidos dispersos, garantindo que a coexistência e a simultaneidade de ações, tempos e espaços numa mesma narrativa produza significados" (NEITZEL, 2009, p. 145). No caso do museu, os engastes são os elementos que o curador lança mão para que o significado da peça seja expandido, aquilo que gera uma transubjetividade do objeto que não pode ser compreendida apenas nas referências objetivas, manifestando riqueza nas ressonâncias. Ele é o responsável pelos disparos imagéticos que temos diante de uma peça - textos caleidoscópicos e espelhados - que vão se compondo em rede.

Um exemplo de engaste encontramos na ala dos tubarões. Alguns espécimes estão colocados em grandes tanques e, em alguns casos, uma luz incide sobre seu couro de forma que o público possa perceber o tom aveludado da pele (Figura 4). O toque é provocado na imaginação e, assim, desmistificamos a ideia de que o tubarão é um animal que não podemos nos aproximar. $\mathrm{O}$ engaste desperta uma amplitude e uma força de detalhes que pode ressoar, e o museu torna-se, então, campo de inumeráveis experiências estésicas. Para Carvalho e Lopes (2018, p. 914), nos museus, por meio do processo de observação e concentração, “[...] ocorre a apropriação de sentidos e de significados que não passam apenas pela dimensão racional, mas também pelo sensível".

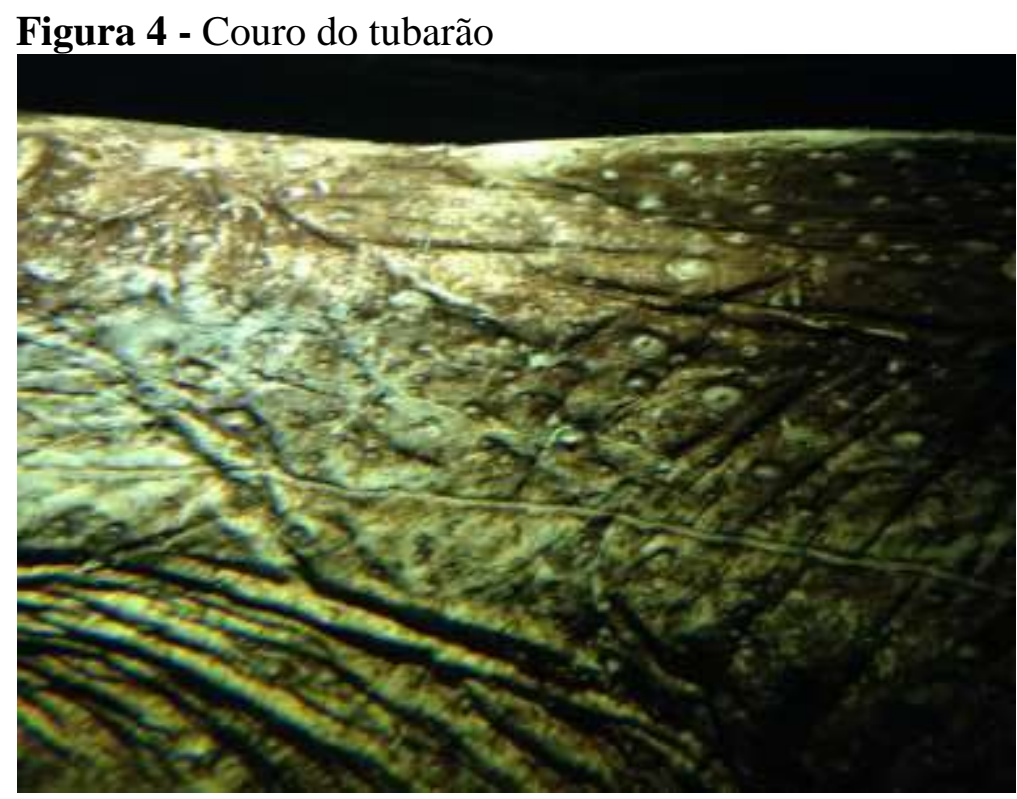

Fonte: Acervo das autoras. 
Diante das provocações curatoriais, é necessário que o público penetre e se deixe embrenhar pelas fissuras e pelos poros que o engaste constituiu, fugindo da armadilha fatal a que nos obriga a ler a função explícita dos objetos museais para adentrar aquilo que está implícito. Quando o público aceita, instaura-se um jogo que o insere em um mundo às avessas, um trabalho de deslocamento, fora da significação usual, girando os saberes, ampliando o significado do objeto catalogado. Nesse sentido, afirmamos que o museu de ciências é o lugar da informação, mas não só, como afirma o curador do MOVI: “'Ah, mais importante do que isso é a informação!'. Não! Eu discordo completamente e minha experiência já me provou que não funciona dessa forma". O curador argumenta que o excesso de informação no museu não reverbera na pessoa, o que comprova que esta não é sua função principal. Segundo o curador: "A pessoa ouve diversos nomes científicos e sai do museu sem ter decorado nenhum. Se for perguntar para ela, ela não sabe repetir nenhum dos nomes que leu. Então, não é esta a função, não é só a informação que a gente tem que dar". Carvalho e Lopes (2016, p. 915) concordam com o curador do MOVI e declaram: "Insistir no acúmulo de explicações e informações sobre as obras e objetos acaba por reduzir o contato com o acervo às suas dimensões técnica e histórica, privando a criança dos momentos de fruição".

Contudo, como nos afetamos por objetos museais? Como entrar nesse jogo de deslocamentos? Barthes (2010) propõe que alguns elementos componentes de um determinado objeto saltam da cena e vem transpassar-nos, pungir-nos, afetando-nos, como um punctum definido como "[...] picada, pequeno orifício, pequena mancha, pequeno corte" (BARTHES, 2010, p. 35). Quando olhamos para o objeto museal e buscamos enxergá-lo para além de sua definição usual, acionamos o punctum, pois abrimos possibilidades para as subjetividades, as quais interferem no jogo entre imaginação e entendimento. Já o studium remete ao que a imagem apresenta objetivamente, aos elementos que a compõem e a forma que estão dispostos.

Punctum e studium, ao serem acionados conjuntamente, provocam o sujeito a identificar o conceito objetivo (studium) do objeto, mas também o subjetivo (punctum). As sensações que temos diante dos tanques de tubarão são completadas quando nos colocamos frente a um expositor de arcadas de tubarões que se encontram abertas (Figura 5), elemento que aciona nosso pensar sobre a ferocidade do animal. Rapidamente, associamos a essa imagem das arcadas filmes, livros, músicas que exploram a violência desse animal, imagem que se contrapõe àquela do couro aveludado do qual discorremos anteriormente. 
Figura 5 - Ala dos tubarões

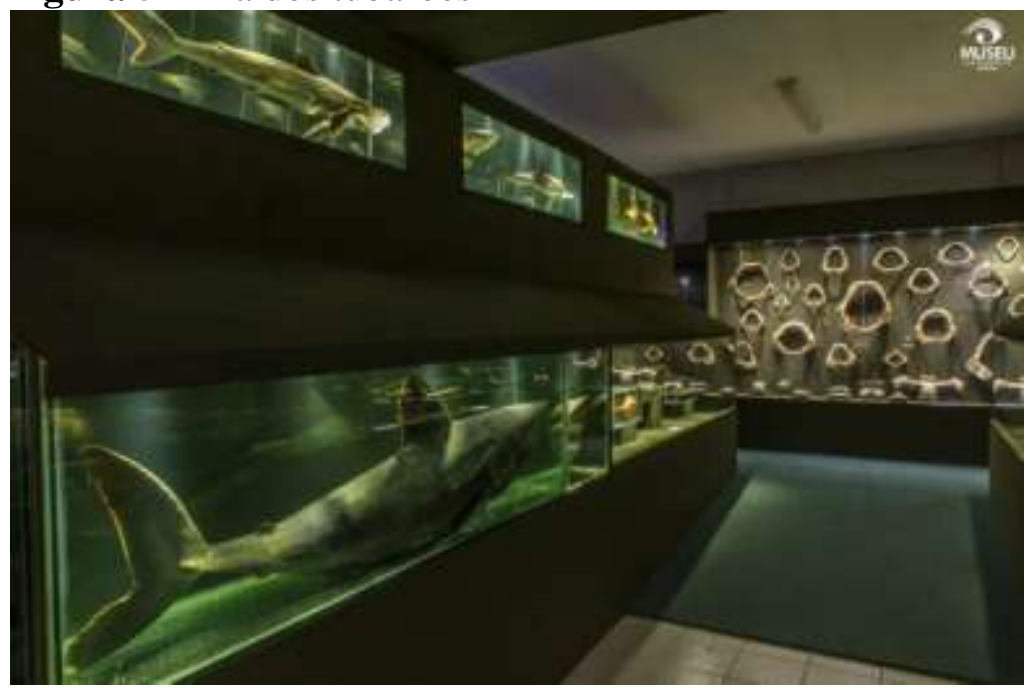

Fonte: MOVI (2019b, n.p.).

Para Barthes (2010), o punctum é um interesse guiado pelas características ligadas ao contexto cultural, à experiência individual de cada pessoa, diz respeito a detalhes que tocam emocionalmente o espectador e variam de pessoa para pessoa. Já o studium tem um caráter objetivo, é um interesse que se impõe pela memória do próprio objeto. Esse jogo entre imaginação e entendimento, entre objetivo e subjetivo pode nos colocar em estado de estesia, refinar nossos sentidos ou promover a educação pelo afeto e pelo conchego que expressam. Um museu que explora para além da capacidade comunicativa dos objetos e investe nos detalhes básicos para a provocação da experiência foge de uma concepção instrumental de museu.

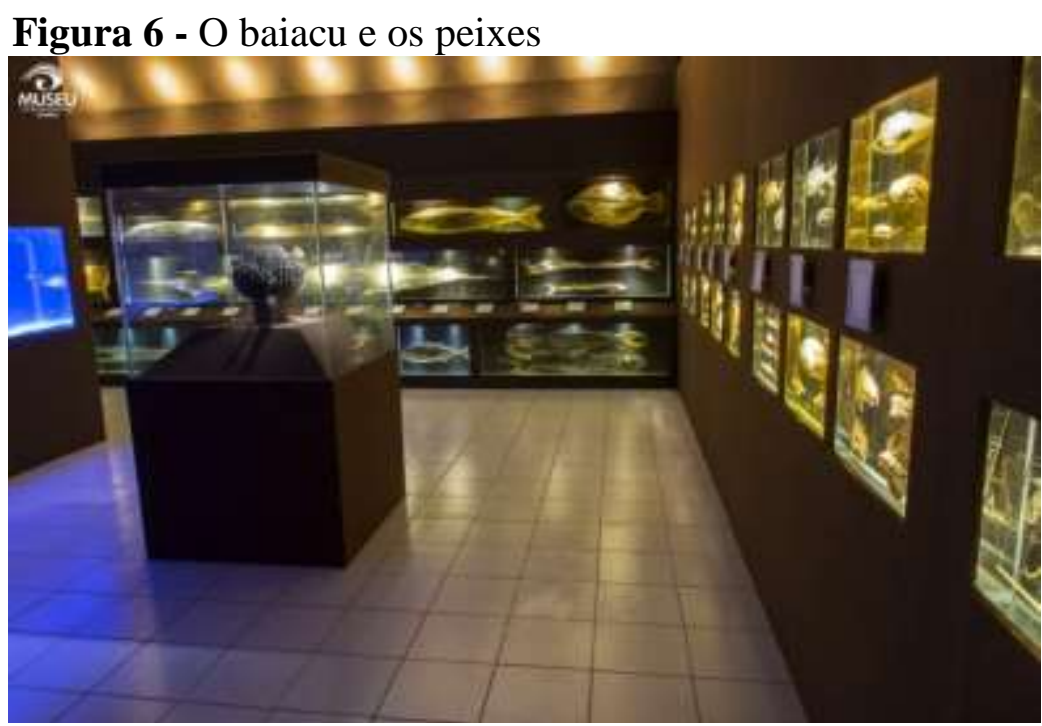

Fonte: MOVI (2019c, n.p.). 
Muitas vezes, o referido punctum é um objeto inserido em um cenário, mas também pode apresentar-se por um pormenor, um detalhe que, de certo modo, nos provoca uma entrega, como o canto das baleias que escutamos quando nos aproximamos do final da exposição. $\mathrm{O}$ som produzido pelas baleias na água é amplificado porque a sua velocidade é maior do que na atmosfera ao nível do mar. É o meio pelo qual elas utilizam para comunicar-se, e, sendo uma linguagem de comunicação, é por meio dela que constroem percepções do meio em que vivem.

Além dos sons que escutamos como canções, podemos tocar nas barbatanas franjadas que se localizam na boca da baleia e filtram os krills e peixes que as alimentam. Pelo toque e pelo som, nossos sentidos são mobilizados e, quando adentramos a última sala de exposição, somos surpreendidos pela visão: a ossatura de baleias suspensas por cabos (Figura 7) nos provoca e convida à estesia. Esse jogo dinâmico entre a imaginação e o entendimento são acionados pelo afetamento, pela experiência e, segundo Carvalho e Lopes (2016, p. 914): "Essas experiências podem permitir que as crianças criem sentidos e conexões capazes de gerar novos significados que ampliarão seu repertório, formando uma rede complexa de simetrias e contraposições".

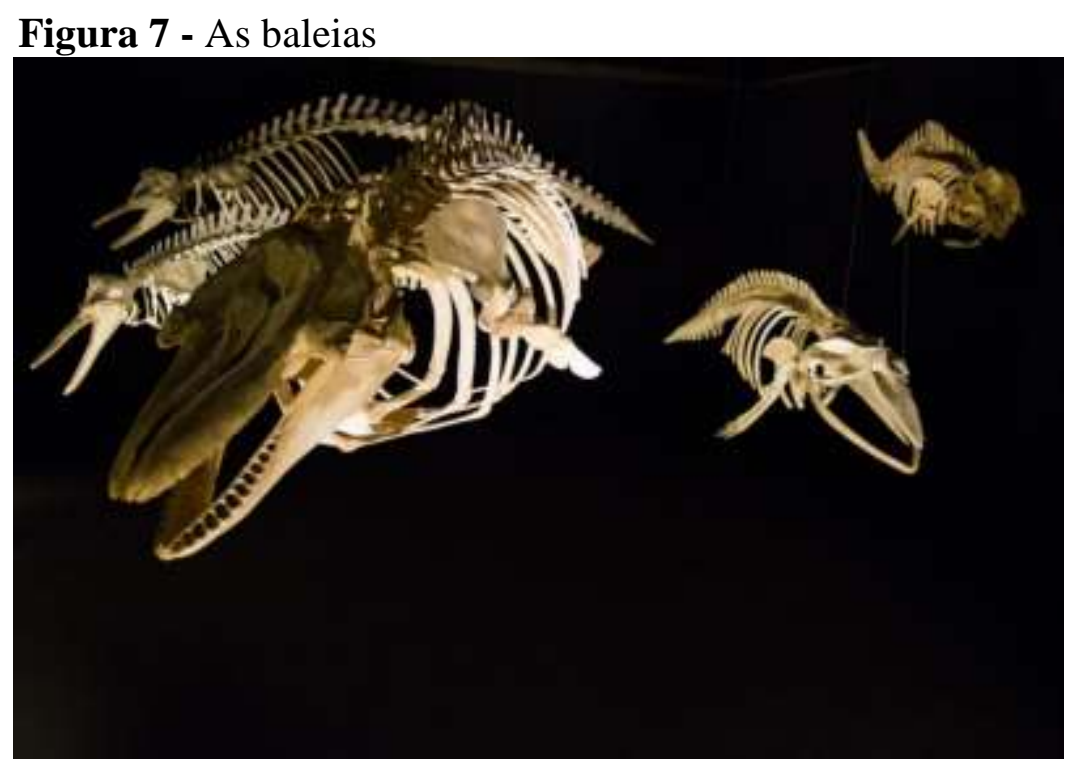

Fonte: MOVI (2019d, n.p.).

Para Heidegger (2015), a experiência não é algo que podemos ter, mas fazer - o "fazer" tem o sentido de atravessar, sofrer, receber - é sempre com alguém ou algo que “[...] nos atropela, nos vem ao encontro, chega até nós, nos avassala e transforma" (HEIDEGGER, 2015, p. 121). A experiência exige de nós ampliar nossas oportunidades de escuta e de visão. Para o autor, a experiência passa pela nossa relação com a linguagem e pelas possibilidades que nos permitimos de fazer com ela. A experiência é “[...] algo que se pode somente fazer e jamais 
ter, por isso ela é vista como acontecimento" (HEIDEGGER, 2015, p. 121). Um acontecimento não é o que acontece, mas o que nos acontece, e a experiência não é um acontecimento geral a todos, mas é algo individual, que nos acontece de forma singular. Duas pessoas podem passar pelo mesmo evento, porém fazem experiências diferentes.

Sinalizamos que as imagens colhidas ao longo da exposição interferem em nosso juízo de gosto e atuam em nosso refinamento estético que nos prepara para a abstração conceitual. Imagens colhidas no movimento entre o punctum e o studium acionam uma força de expansão, do objetivo para o subjetivo e vice versa, de modo a nos impulsionar à elaboração de certas relações que nos faz acrescentar algo, via imaginação e entendimento, na cena ou no objeto observado. Essa experiência não se dá fora do mundo vivido, como enfatiza Duarte Júnior (2012), e o conhecimento conceitual não se dá apartado do mundo sensível.

A tese defendida por Franklin (2019), de que o Museu de Ciências Naturais é um espaço viabilizador de educação estética quando se configura como um lugar do sensível e do inteligível sem apartamentos, o qual oportuniza o conhecimento pela experiência, foi fundante nesta pesquisa. Por meio dela, pudemos entender como exposições em museus de ciências podem provocar movências e apetências pelo "pensar e sentir rentes" (FRANKLIN, 2019, p. 8), pelo jogo entre racionalidade e sensibilidade, de como eles “[...] potencializam a amplidão nas formas do sujeito significar o mundo" (FRANKLIN, 2019, p. 8).

\section{Considerações finais}

Propomo-nos a discutir como o museu de ciências pode ser também espaço de provocação dos sentidos, de educação estética. Compreendemos, por meio desta pesquisa, que, para o museu de ciências ser um espaço estésico, a concepção do projeto do curador é fundamental estar alinhada com essa compreensão porque as opções que ele faz podem ampliar as possibilidades do sujeito da experiência. Percebemos que o projeto do MOVI está repleto de elementos sensíveis (lúdicos, oníricos e afetuais), que repercutem, ampliam nossos sentidos e podem nos afetar. Dessa forma, compreendemos que o museu de ciências tem uma potência estésica que, ao ser explorada pelo curador, pode provocar a educação estética.

Trouxemos aqui a ideia do museu de ciências como espaço de experiência, esta entendida como um acontecimento que nos acontece, que nos atravessa. Assim, pela relação com os objetos e espaços museais, afetamo-nos e passamos a ressignificar os objetos. Reanunciar essa nova ordem pode abrir-nos possibilidades de desembrutecimento e refinamento dos sentidos. A experiência no museu, conforme a proposição aqui trabalhada, não nasce apenas 
de abstrações conceituais, mas da relação que exploramos com os objetos que falam, que comunicam, mas também provocam os sentidos. É por meio deles que formulamos conceitos, por isso sensível e inteligível não podem dar-se apartados.

Buscamos explorar nas imagens registradas no museu os engastes curatoriais que são elementos que o curador lança mão para que o significado da peça seja expandido e que podem provocar o público a habitar esse espaço, a produzir novas imagens. $\mathrm{O}$ engaste é o responsável pela produção de transubjetividades do sujeito da experiência diante do objeto museal, as quais são compreendidas no cotejamento com as potencialidades objetivas do objeto. É, na crise, isto é, na renúncia do conhecimento cristalizado, que se estabelece o lugar do saber sensível, saber que dá espaço para os vazios, de outro modo, quando se ampliam as significações do objeto e enxergamos outros sentidos até então obnubilados.

Em síntese, como resultados sinalizamos: O Museu Oceanográfico da Univali (MOVI) possui espaços esteticamente planejados, cuja organização, iluminação e exploração de sonoridades afetam o sujeito, provocando-o à experiência. Identificamos que as escolhas efetuadas pela curadoria são intencionais para sensibilizar o público e que elas possibilitam que espaços e objetos sejam propositores de se fazer a experiência porque ampliam o potencial estético do museu. No entanto, como a experiência é um movimento individual, nem todos podem por ele ser afetados da mesma forma. 
${ }^{1}$ Univali - Universidade do Vale do Itajaí.

\section{Referências}

BACHELARD, Gaston. A poética do espaço. Tradução Franklin Leopoldo e Silva. São Paulo: Abril Cultural, 2000.

BARTHES, Roland. A câmara clara: nota sobre a fotografia. Lisboa: Edições 70, 2010.

BRASIL. Base Nacional Comum Curricular: educação é a base. Brasília: MEC, 2018.

Disponível em:

http://basenacionalcomum.mec.gov.br/images/BNCC_EI_EF_110518_versaofinal_site.pdf.

Acesso: 3 fev. 2020.

CARVALHO, Cristina; LOPES, Thamiris Lopes. O público infantil nos museus. Educação \& Realidade, Porto Alegre, v. 41, n. 3, p. 911-930, jul./set. 2016. DOI:

http://dx.doi.org/10.1590/2175-623652329.

DUARTE JÚNIOR, João Francisco. Entrevista com João Francisco Duarte Júnior. [Entrevista cedida a] Carla Carvalho. Revista Contrapontos, Itajaí, v. 12, n. 3, p. 362-367, set./dez. 2012. DOI: http://dx.doi.org/10.14210/contrapontos.v12n3.p362-367.

DUARTE JÚNIOR, João Francisco. $O$ sentido dos sentidos: a educação (dos) sentidos. 5. ed. Curitiba: Criar Edições, 2010.

FRANCO, Maria Laura Puglisi Barbosa. Análise de conteúdo. 3. ed. Brasília: Liber Livro, 2008.

FRANKLIN, Kátia. Educação estética: possibilidades no Museu de Ciências Naturais. 2019. 210 f. Tese (Doutorado em Educação) - Universidade do Vale do Itajaí, Itajaí, 2019.

FRANKLIN, Kátia et al. Uma experiência no museu de ciências. In: NEITZEL, Adair Aguiar de et al. (orgs.). Cultura, escola e educação criadora: diálogos sobre experiências estéticas na educação. Itajaí: Univali; Florianópolis: Dois Por Quatro, 2017. p. 137-152.

GOHN, Maria da Glória. Movimentos sociais na contemporaneidade. Revista Brasileira de Educação, Rio de Janeiro, v. 16, n. 47, p. 333-362, maio/ago. 2011.

GOHN, Maria da Glória. Educação não formal no campo das artes. São Paulo: Cortez, 2015. HEIDEGGER, Martin. Caminhos da linguagem. Tradução Marcia Sá Cavalcante Schuback. Petrópolis: Vozes; São Paulo: Editora Universitária São Francisco, 2015.

IBRAM. Instituto Brasileiro de Museus. Caderno da Política Nacional de Educação Museal. Brasília, DF: IBRAM, 2018. Disponível em: https://www.museus.gov.br/wpcontent/uploads/2018/06/Caderno-da-PNEM.pdf. Acesso em: 1 fev. 2020.

LARROSA, Jorge. Tremores: escritos sobre a experiência. 1. ed. 2. reimp. Tradução Cristina Antunes e João Wanderley Geraldi. Belo Horizonte: Autêntica, 2016. 
LAWAND, Diógenes Nicolau. Memória e ensino de história: uma experiência na educação de jovens e adultos. 2004. 290 f. Dissertação (Mestrado em Educação) - Faculdade de Educação, Universidade de São Paulo, São Paulo, 2004.

MARTINS, Maria do Carmo. Educação em museus: didática, currículo e mediação em contextos patrimoniais. ETD - Educação Temática Digital, Campinas, v. 20 n. 3 p. 579-581, jul./set. 2018.

MARTINS, Miriam Celeste. (org.). Pensar juntos a mediação cultural: [entre]laçando experiências e conceitos. São Paulo: Terracota, 2014.

MARTINS, Miriam Celeste. Curadoria educativa: inventando conversas. In: MARTINS, Miriam Celeste; PICOSQUE, Gisa. (Eds.). Mediação Cultural para professores andarilhos da cultura. São Paulo: Intermeios, 2012. p. 61-73.

MOVI. Museu Oceanográfico Univali. Exposição oceanográfica. Ala vermelha Invertebrados. 2019a. 1 fotografia. Disponível em:

https://www.univali.br/institucional/museu-oceanografico-univali/exposicaooceanografica/Paginas/default.aspx. Acesso em: 3 fev. 2020.

MOVI. Museu Oceanográfico Univali. Exposição oceanográfica. Ala verde - cartilaginosos. 2019b. 1 fotografia. Disponível em: https://www.univali.br/institucional/museuoceanografico-univali/exposicao-oceanografica/Paginas/default.aspx. Acesso em: 3 fev. 2020.

MOVI. Museu Oceanográfico Univali. Exposição oceanográfica. Ala marrom - ósseos. 2019c. 1 fotografia. Disponível em: https://www.univali.br/institucional/museu-

oceanografico-univali/exposicao-oceanografica/Paginas/default.aspx. Acesso em: 3 fev. 2020.

MOVI. Museu Oceanográfico Univali. Exposição oceanográfica. Ala preta - mamíferos. 2019d. 1 fotografia. Disponível em: https://www.univali.br/institucional/museuoceanografico-univali/exposicao-oceanografica/Paginas/default.aspx. Acesso em: 3 fev. 2020.

NEITZEL, Adair de Aguiar. O jogo das construções hipertextuais. Florianópolis: UFSC; Itajaí: Univali, 2009.

NEITZEL, Adair Aguiar de et al. Mediações culturais no museu. In: NEITZEL, Adair Aguiar de et al. (orgs.). Cultura, escola e educação criadora: diálogos sobre experiências estéticas na educação. Itajaí: Univali; Florianópolis: Dois Por Quatro, 2017. p. 325-345.

NEITZEL, Adair Aguiar de; PONTES, Maria Cristina Kumm; NEITZEL, Mariana de Aguiar. O museu de ciências como espaço de educação estética. In: URIARTE, Mônica Zewe; NEITZEL, Adair Aguiar de; KRAMES, Ilisabet Pradi. (orgs.). Cultura, Escola e Educação criadora: mediações culturais e proposições estéticas. Curitiba: CRV, 2020. p. 287-311.

NHOQUE, Janete Ribeiro. O leitor encarnado e a leitura do literário como experiência. 2019. 314 f. Tese (Doutorado em Educação) - Universidade do Vale do Itajaí, Itajaí, 2019.

SILVA, Angélica Brito; BITENCOURT, Eron Matheus. Descobrir o museu, (re)descobrir a cidade. ETD-Educação Temática Digital, Campinas, v. 20, n. 3, p. 586-603, jul./set. 2018. DOI: https://doi.org/10.20396/etd.v20i3.8651710. 